\title{
ALINHAMENTO DO INVESTIMENTO SOCIAL AO NEGÓCIO: REFLEXÕES SOBRE O PASSADO, O PRESENTE E O FUTURO
}

\author{
Pamela Dietrich Ribeiro Unterberger
}

\begin{abstract}
// resumo
O alinhamento do investimento social ao negócio é um fenômeno observado há mais de uma década e que está se consolidando como estratégia adotada por empresas para a gestão de seus investimentos sociais. Diferentes formatos e abordagens para o alinhamento são observados, além de potenciais riscos e oportunidades. Este artigo se propõe a refletir sobre como evoluíram os efeitos do alinhamento do investimento social ao negócio e possíveis caminhos para o futuro, contribuindo para o monitoramento das implicações dessa tendência. Os resultados apontam para uma diversificação temática e mudanças nos públicos beneficiados, assim como uma provável restrição de territórios. Relevam novas formas de alinhamento, que posicionam o investimento social como mais estratégico para o negócio, mas que exigem a busca constante e permanente de equilíbrio entre o público e o privado. Mostram o potencial do alinhamento ao negócio de impulsionar a mensuração de resultados. Indicam o fortalecimento de institutos e fundações empresariais, apontando o desafio de preservar seu caráter público e a missão das OSC parceiras.
\end{abstract}

Palavras-chave: alinhamento do investimento social ao negócio | investimento social corporativo | filantropia estratégica. 


\section{OS ARTIGOS GIFE}

A série Artigos GIFE publica reflexões e análises de pesquisadores brasileiros de diferentes áreas do saber com o objetivo de estimular, ampliar e disseminar a produção de conhecimento qualificado sobre o campo da filantropia, do investimento social privado e da sociedade civil no Brasil.

A partir da premissa de que a produção de conhecimento sobre esses temas tem um papel fundamental na expansão, diversificação e qualificação da ação pública pela sociedade, a iniciativa também pretende contribuir para ampliar as conexões entre o setor, as universidades e os centros de pesquisa, promovendo e apoiando o envolvimento de novos atores com a temática e a circulação ampliada de ideias em torno dela.

Este texto integra a quarta edição dos Artigos GIFE, que propõe a publicação mensal de artigos selecionados por meio de chamada pública e convite a autores especialistas em temáticas específicas e relevantes para o setor, buscando apoiar e fomentar a produção de conhecimento sobre o investimento social no Brasil.

\section{O GIFE}

O Grupo de Institutos Fundações e Empresas (GIFE) é uma organização sem fins lucrativos que reúne associados de origem empresarial, familiar ou independente que investem em projetos de interesse público. Criado em 1989 como grupo de troca e colaboração e institucionalizado em 1995 por 25 organizações, tornou-se referência no campo da filantropia e do investimento social privado no Brasil.

Nesses mais de 20 anos de atuação, tem contribuído para o fortalecimento de práticas e ações a serviço do bem comum no país, trabalhando para expandir, qualificar e fortalecer o investimento social privado, diversificar e ampliar atores e recursos, criando referências e estimulando boas práticas de gestão, bem como articulando o setor com a sociedade e a agenda pública. Atualmente, o GIFE reúne mais de 150 associados que, somados, aportam mais de $\mathrm{R} \$ 3$ bilhões por ano em projetos próprios e no apoio a projetos de terceiros. 


\section{artigos \\ GIFE}

\section{INTRODUÇÃO}

O alinhamento do investimento social ao negócio é um fenômeno recente e que tem efeitos ainda pouco conhecidos. Iniciado na década de 2000 , passou a ser cada vez mais adotado como estratégia de gestão dos investimentos sociais corporativos na década seguinte, sendo que, em 2018, 76\% dos 17 institutos empresariais e 92\% das 254 empresas respondentes da pesquisa Benchmarking do Investimento Social Corporativo (BISC) ${ }^{1}$ tinham pelo menos uma parte de seus investimentos sociais alinhados ao negócio (COMUNITAS, 2020). A perspectiva é que esse fenômeno se consolide cada vez mais entre os investidores sociais empresariais: $71 \%$ dos respondentes afirmam querer aprofundar o alinhamento dos projetos sociais ao negócio, sendo esse o principal objetivo estratégico das instituições do BISC para os próximos anos (COMUNITAS, 2020).

O investimento social corporativo tem grande relevância no Brasil. Dos 133 respondentes da última edição do Censo GIFE² (GIFE, 2019), 65\% são de origem empresarial (empresas ou institutos e fundações empresariais). O volume investido por esse conjunto de organizações corresponde a aproximadamente $78 \%$ do total investido pela totalidade de respondentes da pesquisa, que inclui também investidores sociais de origem familiar e independente. Em razão da importância que o investimento social de origem empresarial tem no Brasil, torna-se imprescindível conhecer e monitorar as tendências que acompanham esse perfil de instituições.

O Censo GIFE e o BISC vêm monitorando a evolução do alinhamento do investimento social aos objetivos de negócio há quase uma década. Em 2016, foram publicados dois estudos sobre o tema, um liderado pelo GIFE (OLIVA, 2016) e outro pelo Centro de Estudos em Sustentabilidade da FGV-SP (PAGOTTO et al., 2016), permitindo o aprofundamento do conhecimento sobre o fenômeno. Passados quatro anos, este artigo se propõe a refletir, à luz dos achados dos estudos publicados em 2016 e a partir dos dados das edições mais recentes do Censo GIFE (2019) e do BISC (COMUNITAS, 2020), sobre como evoluíram os efeitos do alinhamento do investimento social ao negócio e os possíveis caminhos para o futuro. Sem a pretensão de chegar a conclusões definitivas, espera-se contribuir para o monitoramento contínuo das implicações que o alinhamento pode ter nas estratégias e na gestão dos investimentos sociais corporativos.

$\mathrm{O}$ artigo se divide em cinco partes. A primeira faz um breve resumo da história do investimento social corporativo no país, desde a origem da filantropia até a forma como se apresenta atualmente. A segunda apresenta as características do alinhamento do investimento social ao negócio, destacando diferentes formatos e abordagens. A terceira discute as principais razões para o movimento de alinhamento dos investimentos sociais ao negócio no Brasil, comparando-as com o ocorrido em outros países. A quarta analisa dados históricos e atuais do alinhamento do investimento social ao negócio e reflete sobre a evolução do movimento, as implicações para o campo e os possíveis caminhos para o futuro. Por fim, são apresentadas considerações finais.

1 O BISC é uma pesquisa realizada anualmente pela Comunitas desde 2008, sobre investimentos sociais empresariais, realizados por empresas, institutos e fundações empresariais.

2 O Censo GIFE é uma pesquisa bienal quantitativa, autodeclaratória e voluntária realizada pelo GIFE desde 2001, com empresas, institutos e fundações corporativos, independentes e familiares associados. 


\section{A HISTÓRIA DO INVESTIMENTO SOCIAL CORPORATIVO NO BRASIL}

A forma como a filantropia se desenvolveu no Brasil tem forte influência de seu caráter predominantemente corporativo e da importância que esse perfil de investidor tem para o campo. Tendo sua origem na Igreja Católica, que se instalou no país após a colonização, a filantropia foi, durante alguns séculos, financiada por doações de famílias abastadas e pela realeza, provendo importantes serviços básicos à população, como educação, saúde e assistência social (ROSSETTI, 2010).

Após a independência do país, na década de 1820, algumas leis promulgadas determinaram que o Estado assumisse o papel de provedor de serviços públicos, responsabilizando-se pela oferta de educação básica em todas as cidades e vilas. A Constituição de 1934 reforçou o papel do Estado como provedor de direitos sociais básicos, tais como o acesso à educação básica gratuita e a serviços de saúde e assistência social (PAGOTTO et al., 2016).

No entanto, o processo de industrialização pelo qual o país passou na primeira metade do século XX resultou no acúmulo de riqueza por famílias empresárias brasileiras, retornando a prática da filantropia a partir de recursos privados observada em séculos anteriores, porém com características diferentes. Os recursos filantrópicos eram aplicados principalmente em atividades sociais e culturais, em benefício de funcionários e de suas famílias (ROSSETTI, 2010).

O período de ditadura militar, entre 1964 e 1985, mudou radicalmente o cenário de atuação das organizações da sociedade civil (OSC) no Brasil. Submetidas a forte controle do Estado, elas passaram a depender principalmente de recursos da Igreja Católica e da cooperação internacional. Apesar das restrições impostas à atuação das OSC nesse período, elas tiveram um papel determinante no enfrentamento da ditadura militar e na redemocratização do Estado brasileiro (LANDIM, 2002).

Ao mesmo tempo, o processo de democratização redefiniu a organização da sociedade civil e os papéis assumidos por cada ator. A partir da década de 1990, a esfera pública, dominada até então pelo Estado, passou a ter responsabilidade compartilhada entre os três setores da economia - Estado, empresas privadas e OSC (DEGENSZAJN e RIBEIRO, 2013).

Esse cenário de novos papéis atribuídos à iniciativa privada, aliado ao movimento global da responsabilidade social empresarial, intensificou no Brasil as cobranças às empresas pela responsabilidade não apenas por seu desempenho econômico, mas também por seus impactos sociais e ambientais (PORTER e KRAMER, 2007). A criação formal do GIFE e do Instituto Ethos nesse período foi uma resposta à crescente cobrança ao setor privado brasileiro por respostas a temas de interesse público. Portanto, é nesse contexto de fortalecimento do Estado democrático, de consolidação e crescimento do terceiro setor e de intensificação das reivindicações às empresas privadas que surge o conceito de investimento social privado (ISP) no Brasil.

Cunhado por empresários e executivos de empresas que deram origem ao GIFE, o ISP, ainda que não seja restrito à prática filantrópica de empresas privadas, tem forte influência da visão empresarial. Definido pelo GIFE como "o repasse voluntário de recursos privados de forma planejada, monitorada e sistemática para projetos sociais, ambientais, culturais e científicos de interesse público" (GIFE, s.d.), o termo ISP busca diferenciar essa prática da filantropia de caráter mais assistencialista e de ajuda pontual. Por outro lado, a definição reforça a finalidade pública do ISP, com o objetivo de distingui-lo das ações de responsabilidade social da empresa voltadas ao público interno, com a clara intenção de apartar aquilo que é de interesse privado do que é de interesse público e evitar a contaminação do público pelo privado (DEGENSZAJN e RIBEIRO, 2013).

O distanciamento do investimento social corporativo do negócio começou a tomar novos rumos a partir dos anos 2000, quando se observava uma tendência crescente de alinhamento das estratégias de investimento social empresarial às estratégias de negócio (ROSSETTI, 2010). Os dados da última edição do Censo GIFE mostram uma percepção de consolidação do alinhamento ao negócio como uma tendência no campo do investimento social corporativo: $71 \%$ das empresas e $65 \%$ dos institutos e fundações empresariais respondentes perceberam um aumento do alinhamento ao negócio nos últimos dois anos (GIFE, 2019). 


\section{CARACTERÍSTICAS DO ALINHAMENTO DO INVESTIMENTO SOCIAL AO NEGÓCIO}

Mas afinal, o que é alinhamento ao negócio? O entendimento geral dos respondentes do BISC é que corresponde à "adoção de práticas relacionadas ao core business das empresas e que geram, simultaneamente, benefícios para as comunidades e os negócios” (COMUNITAS, 2015, p. 99). Segundo a pesquisa, o alinhamento ao negócio, na prática, é muito particular de cada instituição, a depender da missão e dos valores da empresa, das estratégias e prioridades de negócio, do setor de atividade econômica, do porte da empresa, das relações que a empresa deseja estabelecer com cada parte interessada, entre outros fatores (COMUNITAS, 2015). Portanto, pode-se dizer que há formas muito variadas de se compreender o alinhamento ao negócio e formatos distintos de como acontece.

Pagotto et al. (2016) identificaram cinco principais formatos de ocorrência do alinhamento: geográfico, por público de interesse, temático, por modelo de gestão e institucional. No alinhamento geográfico, o território diretamente impactado pelas atividades empresariais é o fator determinante das prioridades do investidor social. No alinhamento por públicos de interesse, os atores que estão na esfera de relacionamento com o negócio - como funcionários, consumidores/ clientes e fornecedores - determinam a estratégia de investimento. No alinhamento temático, as prioridades de investimento são determinadas por temas de interesse do próprio investidor e do negócio, por estarem relacionados ao core do negócio, aos produtos e serviços ofertados, aos públicos de interesse ou aos processos produtivos. $\mathrm{O}$ alinhamento pode acontecer também por modelo de gestão, ou seja, os processos internos adotados no investimento social se aproximam dos modelos de gestão do negócio. Por fim, o alinhamento institucional acontece quando há orientações de pessoas externas ao negócio e ao investimento social, em geral de controladores, para que potenciais sinergias sejam encontradas e esforços e investimentos sejam combinados para a geração de ganhos mútuos (PAGOTTO et al., 2016).

Os formatos de alinhamento adotados por investidores sociais corporativos são determinados pelo que se espera de benefícios ou retornos com o alinhamento. O relatório BISC 2018 elenca uma grande variedade de potenciais benefícios esperados pelos respondentes. A melhoria no diálogo com partes interessadas, a aproximação com as comunidades e o fortalecimento da imagem da empresa são as principais expectativas de retorno, sendo muito altas para $54 \%, 46 \% \mathrm{e}$ $38 \%$ dos respondentes, respectivamente (COMUNITAS, 2018).

Oliva (2016) identificou quatro abordagens diferentes da aproximação do investimento social ao negócio: incrementalista, influência social estratégica, valor compartilhado e inteligência social dos negócios. A abordagem incrementalista tem a preocupação de preservar a identidade e a autonomia do investimento social, porém busca sinergias entre as duas partes, como ganhos reputacionais, engajamento e voluntariado e construção de relacionamento com partes interessadas. A abordagem de influência social estratégica entende que o investimento social tem o papel de qualificar a atuação socioambiental do negócio e deve ajudá-lo a ter bom desempenho nesses aspectos, como uma espécie de advocacy interno ou watchdog do desempenho socioambiental das áreas de negócio. A abordagem chamada de valor compartilhado entende que a estratégia de investimento social deve se pautar pela geração de valor, tanto para a sociedade quanto para o negócio, buscando relações de ganha-ganha. Por fim, na abordagem de inteligência social de negócios, o investimento social deve atuar como uma unidade de inteligência social, apoiando o desenvolvimento de novas soluções de negócio para a resolução de problemas sociais ou ambientais ou identificando negócios de impacto com potencial de se associar à empresa (OLIVA, 2016).

Um investidor social pode adotar uma ou mais abordagens na sua estratégia de alinhamento ao negócio, dependendo do que espera atingir e do seu contexto de operação. 


\section{RAZÕES PARA O ALINHAMENTO DO INVESTIMENTO SOCIAL AO NEGÓCIO}

Entre os principais motivos para o movimento de alinhamento do investimento social ao negócio estão a minimização de custos, pela convergência de esforços e investimentos, e uma maior legitimidade e perenidade do investimento social, na medida em que ele passa a gerar benefícios para o negócio e se torna mais fácil justificá-lo (PAGOTTO et al., 2016).

A conjuntura econômica do país se reflete no volume de recursos disponibilizadas para atividades de investimento social, como apontado na última edição do BISC (COMUNITAS, 2020) e do Censo GIFE (2019). Em virtude dessas oscilações, gestores de investimento social são cada vez mais pressionados a mostrar o valor que o investimento social gera para o negócio e o seu alinhamento se torna uma estratégia cada vez mais adotada.

Esse movimento não é exclusivo do Brasil. Em especial a partir da década de 1990, gestores de fundações corporativas norte-americanas também foram constantemente pressionados a justificar a existência e a relevância das atividades filantrópicas para o negócio (SAIIA, CARROLL e BUCHHOLTZ, 2003). As pressões internas, somadas às cobranças externas da sociedade para que as empresas dessem visibilidade às suas ações frente aos desafios sociais e ambientais, deram origem ao que ficou conhecido como filantropia estratégica (strategic philanthropy). O conceito de filantropia estratégica está ancorado na crença de que a filantropia deve gerar valor para a sociedade, mas também para o negócio (KUBÍCKOVÁ, 2018).

A ideia de valor compartilhado, amplamente difundida por Porter e Kramer (2011), parte da premissa de que a sociedade e os negócios são interdependentes e que, portanto, as necessidades sociais definem o mercado. Dessa forma, os princípios de valor compartilhado "envolvem criar valor econômico de forma a também criar valor para a sociedade, atendendo a suas necessidades e seus desafios" (PORTER e KRAMER, 2011, p. 64). Esse olhar sobre a relação entre empresa e sociedade responde à aparente contradição entre a Teoria do Acionista, em que gestores não deveriam distribuir recursos dos acionistas por puro altruísmo, e a Teoria das Partes Interessadas, em que gestores devem levar em consideração os interesses de todas as partes interessadas do negócio e não apenas dos acionistas (KUBÍCKOVÁ, 2018).

O que diferencia a filantropia corporativa estratégica de outras formas de filantropia corporativa é a conexão clara entre as atividades filantrópicas e os resultados para a estratégia de negócio, de tal forma que possam ser mensurados de forma clara e objetiva (LIKET e MAAS, 2016). Chatterjee e Rai defendem três elementos esperados da filantropia corporativa estratégica: “(a) estabelecer objetivos claramente definidos, (b) explorar e perseguir estratégias baseadas em evidência, (c) monitorar o progresso e avaliar o sucesso junto aos donatários” (2017, p. 400).

\section{IMPLICAÇÕES E CAMINHOS DO ALINHAMENTO DO INVESTIMENTO SOCIAL AO NEGÓCIO}

As razões para o movimento de alinhamento do investimento social ao negócio parecem se assemelhar às que levaram à consolidação da filantropia corporativa estratégica nos Estados Unidos e em outros países. Porém, os efeitos desse movimento são particulares do contexto brasileiro. Oliva (2016) e Pagotto et al. (2016) se dedicaram a entender os potenciais riscos e oportunidades desse alinhamento, a partir de dados disponíveis e conversas com gestores e especialistas. Passados quatro anos, apesar de o fenômeno ainda ser recente, já é possível observar nos resultados das últimas edições das pesquisas BISC (COMUNITAS, 2020) e Censo GIFE (2019) alguns indícios da evolução das implicações do alinhamento ao negócio e possíveis caminhos para o investimento social corporativo no futuro.

\subsection{Públicos, territórios e temáticas}

Entre os riscos apontados por Oliva (2016) e Pagotto et al. (2016), está a redução da abrangência temática, territorial e de públicos do investimento social corporativo no país. Dados da última edição do BISC 
(COMUNITAS, 2020) reforçam essa preocupação, mas apontam para uma mudança potencialmente positiva nos públicos priorizados.

Historicamente, sabe-se que crianças e jovens são os públicos-alvo predominantes de investidores sociais. Em 2011, 96\% dos respondentes do BISC tinham como público-alvo jovens e, $83 \%$, crianças e adolescentes. Em 2018, o cenário mudou um pouco. Apesar de jovens, crianças e adolescentes terem se mantido como públicos relevantes $(73 \%)$, cresceu de forma significativa a importância das comunidades do entorno das empresas ( $74 \%$ em 2011 e 87\% em 2018) e da população adulta (72\% em 2011 e 80\% em 2018) como público-alvo dos investidores sociais corporativos. Pode-se dizer que a mudança nos públicos priorizados é reflexo de um efeito importante do alinhamento ao negócio, apontado também pela última edição do BISC: o fator construção de relacionamento com a comunidade foi indicado como o principal direcionador da estratégia do investimento social corporativo (COMUNITAS, 2012, 2020).

Esse efeito também tem impacto nos territórios e nas temáticas priorizadas. Temas mais consensuais, como educação e formação de jovens, sempre foram privilegiados por investidores sociais, em detrimento daqueles mais controversos, como direitos humanos. Porém, contrariando os temores de que o alinhamento ao negócio reforçaria ainda mais essa tendência, parece que o desejo de construção de relacionamento com as comunidades demanda a consideração de toda a diversidade de necessidades locais na definição das temáticas prioritárias de investimento. Os dados do BISC 2019 mostram que, em especial para as indústrias que operam nessa lógica de desenvolvimento do entorno, isso é verdadeiro. Enquanto $63 \%$ dos investimentos sociais do setor de serviços são direcionados para educação, o percentual cai para $8 \%$ no caso do setor industrial. Isso também ajuda a explicar os $11 \%$ de investimentos sociais alocados na defesa de direitos humanos por parte das indústrias, percentual muito acima da média do grupo (COMUNITAS, 2020).

Em relação à questão territorial, os investimentos sociais corporativos foram, tradicionalmente, concentrados na região Sudeste, onde grande parte dos negócios possuem sede. Porém, os dados mostram um gradual crescimento de investimentos sociais nas regiões Centro-Oeste, Norte e Nordeste. Em 2011, as três regiões somadas recebiam 18\% dos investimentos sociais dos respondentes do BISC. Em 2013, o montante cresceu para $25 \%$, chegando a $35 \%$ em 2018. A mudança territorial não parece ser reflexo de uma estratégia de pulverização espacial dos investimentos sociais, na medida em que o percentual de investimentos sociais aplicados em regiões diversas caiu entre 2011 (48\%) e 2018 (36\%), mas da expansão dos negócios e da necessidade de construção de relacionamento com as comunidades dos novos territórios (COMUNITAS, 2020).

\subsection{Equilíbrio entre o público e o privado}

Um risco importante apontado por gestores e especialistas do campo está relacionado à subordinação dos interesses públicos aos interesses privados do negócio. Os resultados da última edição do BISC reforçam essa preocupação. Diferente do observado em edições anteriores, um percentual significativo de empresas (58\%) e de institutos (50\%) afirmaram que chegaram a encerrar projetos sociais não alinhados aos objetivos de negócio, indicando rupturas maiores nas estratégias de investimento social, cada vez mais alinhadas aos interesses privados (COMUNITAS, 2020).

A pesquisa mostra ainda que $66 \%$ dos institutos respondentes disseram ter introduzido ou fortalecido a prestação de serviços para a empresa mantenedora no campo social como estratégia de alinhamento ao negócio nos últimos três anos. Além disso, $29 \%$ dos institutos respondentes disseram ter introduzido a estratégia de redirecionamento dos conteúdos dos projetos sociais para adequá-los às potencialidades dos negócios da empresa, e $70 \%$ das empresas respondentes reforçaram a estratégia de alinhamento no mesmo período (COMUNITAS, 2020). Se, por um lado, esses movimentos fortalecem o papel do investimento social como inteligência social do negócio - oportunidade também apontada por Pagotto et al. (2016) -, por outro indicam que a preocupação com o risco de subordinação por parte dos gestores de investimento social e a busca pela geração de valor verdadeiramente compartilhado deve ser constante e permanente. 


\subsection{Inovação e negócios de impacto}

Outra preocupação registrada por Pagotto et al. (2016) para o alinhamento do investimento social ao negócio é o potencial de inibir inovações. O investimento social é muitas vezes entendido como um laboratório de inovações sociais, na medida em que consegue propor e testar com maior facilidade e celeridade soluções para o bem público. A aproximação com os objetivos de negócio pode impor restrições a esse papel do investimento social, em função de mudanças nas prioridades e nos tempos de retorno exigidos pelo negócio. O crescente investimento em negócios de impacto pode ser uma resposta e um provável caminho para o equilíbrio entre o papel do investimento como inovador social e os tempos e focos exigidos pelo negócio. Dados do BISC 2019 reforçam essa tendência observada há alguns anos: o apoio a startups sociais foi uma estratégia de alinhamento ao negócio introduzida por $22 \%$ e fortalecida por $44 \%$ das empresas respondentes nos últimos três anos (COMUNITAS, 2020). Mas, ao olhar para a autoavaliação realizada por institutos e empresas em relação à sua flexibilidade e inovação, nota-se que há espaço para avanços, em especial para empresas: em uma escala de 0 a 10, a nota média dos institutos foi 7,9 e, das empresas, 7,0.

\subsection{Mensuração do impacto e do retorno}

Uma das características da filantropia estratégica observada em outros países é a preocupação com a avaliação dos impactos e retornos das atividades filantrópicas, para a sociedade e para o negócio, respectivamente (LIKET e MAAS, 2016). No Brasil, apesar de a mensuração dos retornos ser um dos motivadores do alinhamento ao negócio, na prática ainda é um desafio. O relatório BISC 2015 mostrava que, para $63 \%$ dos respondentes, os dados sobre o retorno para as empresas estavam disponíveis apenas informalmente e, para 21\%, inexistiam (COMUNITAS, 2015). Portanto, apesar da clareza nos retornos esperados, os instrumentos para medi-los não eram suficientes para aferi-los. O desafio permanece até hoje. A última edição do BISC mostra que 13\% das empresas e $44 \%$ dos institutos diziam dispor de informações quantitativas e/ ou qualitativas, devidamente analisadas, sobre os impactos decorrentes da execução dos projetos; e somente $25 \%$ das empresas e $22 \%$ dos institutos dispunham de informações mensuradas sobre resultados tangíveis do retorno dos investimentos sociais para os negócios (COMUNITAS, 2020). Considerando a intenção dos respondentes da pesquisa de aprofundar o alinhamento nos próximos anos, faz-se necessário avançar na mensuração dos impactos para a sociedade e dos retornos para o negócio, sempre com o cuidado de não deixar que as métricas empresariais prevaleçam sobre a avaliação das atividades de investimento social, preocupação apontada por Pagotto et al. (2016).

\subsection{Fortalecimento dos institutos empresariais e enfraquecimento das OSC}

O alinhamento dos investimentos sociais ao negócio parece estar fortalecendo ainda mais o papel dos institutos e fundações empresariais como parceiros para a atuação social de empresas, reforçando algumas oportunidades apontadas por Pagotto et al. (2016), como o fortalecimento do papel do instituto ou fundação na tomada de decisão empresarial e uma maior probabilidade de sustentabilidade financeira do instituto ou fundação, e afastando o temor de que institutos e fundações deixariam de existir (OLIVA, 2016). Dados da última edição do BISC mostram que desde 2015 o volume de recursos investidos por institutos corporativos vem crescendo em ritmo lento e constante (COMUNITAS, 2020). O volume investido por empresas, por outro lado, caiu drasticamente no mesmo período. Isso indica que as empresas podem estar optando por conduzir sua estratégia de alinhamento ao negócio por meio dos institutos, que ficam responsáveis por executar projetos sociais, com equipes profissionais e especializadas. Os dados mostram que, enquanto as empresas financiam principalmente projetos de terceiros (57\%), muito em razão de suas estruturas enxutas, a maioria dos institutos (64\%) executam projetos próprios (COMUNITAS, 2020).

Esse resultado reforça um risco apontado por Pagotto et al. (2016) e bastante debatido pelo campo, de redução do caráter técnico e político das OSC parceiras. Quando institutos assumem o papel de executar projetos sociais, as OSC precisam se adaptar a essa demanda das empresas e se tornarem prestadoras de serviço, em vez de receptoras de doações. A provável consequência é o distanciamento da sociedade civil organizada de suas agendas e missões e o enfraquecimento do setor como um todo. Portanto, 
fica o questionamento se o fortalecimento dos institutos empresariais passa necessariamente pelo enfraquecimento da sociedade civil organizada e quais seriam as possíveis alternativas.

\section{CONSIDERAÇÕES FINAIS}

A análise de dados históricos e mais atuais sobre o alinhamento do investimento social ao negócio reforça alguns dos desafios apontados por estudos anteriores, mas também refuta riscos e confirma oportunidades identificadas (OLIVA, 2016; PAGOTTO et al., 2016). O investimento social alinhado ao negócio parece caminhar para a concentração dos recursos em territórios de interesse empresarial, ao mesmo tempo em que está diversificando as temáticas trabalhadas e mudando os públicos priorizados em decorrência da lógica territorial de atuação. As novas estratégias adotadas nos últimos anos podem estar colocando o investimento social em posição de subordinação ao negócio e enfraquecendo seu caráter público. Mas, se tomados os devidos cuidados, podem posicioná-lo também como uma unidade de inteligência social para o negócio, equilibrando seus interesses com os benefícios sociais gerados. A crescente atenção dada aos negócios de impacto não apenas exemplifica uma forma de o investimento social se posicionar como uma unidade de inteligência social dos negócios, como mostra o potencial de ampliar o papel inovador do investimento social.

Os dados analisados mostram que a avaliação ainda é um desafio no campo do investimento social, e o alinhamento do investimento social reforça cada vez mais a necessidade de mensuração dos resultados, tanto para o negócio quanto para a sociedade. Com os devidos cuidados para que as métricas empresariais não se sobreponham às sociais, a pressão por mensurar resultados pode acelerar os avanços no campo da avaliação. Por fim, os dados apontam para um fortalecimento cada vez maior dos institutos e fundações empresariais como parceiros capazes de agregar valor ao negócio. Essa é uma oportunidade que se abre ao investimento social alinhado ao negócio. Porém, além da busca constante e permanente por preservar a missão pública do instituto ou fundação, é preciso cuidar da natureza da relação com as OSC, para que elas também não se afastem das suas agendas e missão e não percam seu caráter técnico e político.

Este artigo se propôs a refletir sobre a evolução dos efeitos do alinhamento do investimento social ao negócio e os possíveis caminhos para o futuro, contribuindo para o monitoramento das implicações desse fenômeno nas estratégias e na gestão dos investimentos sociais corporativos. O método baseado exclusivamente em análise documental é uma limitação deste estudo. Apesar de abrangentes, as duas pesquisas consideradas neste estudo se limitam aos universos dos associados GIFE e do grupo BISC. Investigações futuras poderiam considerar a inclusão de investidores sociais que estão fora desse universo, além de agregar novas dimensões de análise relacionadas aos efeitos do alinhamento ao negócio e recortes para comparação entre diferentes perfis de investidores sociais. 


\section{REFERÊNCIAS}

CHATTERJEE, Anusha; RAI, Abha. Strategic philanthropy and its challenges in India: a multiple case study of grantmaking organizations. Nonprofit Management and Leadership, v. 28, n. 3, p. 399-411, 2018.

COMUNITAS. Relatório BISC 2012. 2012. Disponível em: https://www.comunitas.org/wp-content/uploads/2019/11/ BISC_2012_Relat\%C3\%B3rioFinal.pdf. Acesso em: 14 mar. 2020.

COMUNITAS. Relatório BISC 2015. 2015. Disponível em: https://sinapse.gife.org.br/download/relatorio-bisc-de-2015. Acesso em: 14 mar. 2020.

COMUNITAS. Relatório BISC 2018. 2018. Disponível em: https://sinapse.gife.org.br/download/relatorio-bisc-2018. Acesso em: 14 mar. 2020.

COMUNITAS. Relatório BISC 2019. 2020. Disponível em: https://sinapse.gife.org.br/download/relatorio-bisc-2019. Acesso em: 14 mar. 2020

DEGENSZAJN, Andre; RIBEIRO, Pamela. O investimento social em movimento. In: DEBONI, Fabio (org.). Investimento social privado no Brasil: tendências, desafios e potencialidades. Brasília: Instituto Sabin, 2013, p. 19-30.

GIFE - Grupo de Institutos Fundações e Empresas. Censo GIFE 2018. 2019. Disponível em: https://sinapse.gife.org.br/ download/censo-gife-2018. Acesso em: 14 mar. 2020.

GIFE - Grupo de Institutos Fundações e Empresas. Investimento social privado. [s.d.]. Disponível em: https://gife.org.br/ investimento-socialprivado/. Acesso em: 14 mar. 2020.

KUBÍČKOVÁ, Klára. Strategic philanthropy: literature review. Acta Oeconomica Pragensia, v. 2018, n. 3, p. 70-89, 2018.

LANDIM, Leilah. Múltiplas identidades das ONGs. In: HADDAD, Sérgio (org.). ONGs e universidades: desafios para a cooperação na América Latina. Rio de Janeiro: Abong; Peirópolis, 2002, p. 17-50.

LIKET, Kellie; MAAS, Karen. Strategic philanthropy: corporate measurement of philanthropic impacts as a requirement for a "happy marriage" of business and society. Business \& Society, v. 55, n. 6, p. 889-921, 2016.

OLIVA, Rafael. Alinhamento entre o investimento social privado e o negócio. São Paulo: GIFE, 2016. Disponível em: https:// sinapse.gife.org.br/download/alinhamento-entre-o-investimento-social-privado-e-o-negocio. Acesso em: 16 mai. 2020.

PAGOTTO, Lívia M.; BELINKY, Aron; MACEDO, Fernanda; YAMAHAKI, Camila. Entre o público e o privado: caminhos do alinhamento entre o investimento social privado e o negócio. São Paulo: GVces, 2016. Disponível em: https://sinapse. gife.org.br/download/entre-o-publico-e-o-privado-caminhos-do-alinhamento-entre-o-investimento-social-privado-e-o-negocio. Acesso em: 16 mai. 2020.

PORTER, Michael E.; KRAMER, Mark R. The link between competitive advantage and corporate social responsibility. Harvard Business Review, v. 84, n. 12, p. 78-92, 2007.

PORTER, Michael E.; KRAMER, Mark R. Creating shared value: how to reinvent capitalism - and unleash a wave of innovation and growth. Harvard Business Review, v. 89, n. 1-2, p. 62-77, 2011.

ROSSETTI, Fernando. Da filantropia ao investimento social privado. In: MACDONALD, Norine; BORMS, Luc T. (orgs.). Filantropia global. Tradução de Gonçalo Praça, Maria João Ferro e Patrícia Xavier. 1. ed. Lisboa: Centro Português de Fundações, 2010, p. 265-279.

SAIIA, David H.; CARROLL, Archie B.; BUCHHOLTZ, Ann K. Philanthropy as strategy: when corporate charity "begins at home”. Business \& Society, v. 42, n. 2, p. 169-201, 2003. 


\section{A AUTORA}

\section{Pamela Dietrich Ribeiro Unterberger pamidru@gmail.com}

Mestre em Administração de Empresas, na linha de pesquisa de marketing, pela Fundação Getúlio Vargas (FGV), e bacharel em Relações Internacionais pela Pontifícia Universidade Católica (PUCSP). Trabalhou com pesquisa e gestão de conhecimento no GIFE, na Worldwide Initiatives for Grantmaker Support (WINGS) e na Edelman Brasil e coordenou a área de investimento social e responsabilidade social da FTD Educação. Atualmente faz mestrado em Gestão para a Competitividade, na linha de pesquisa de sustentabilidade, na FGV. Integra a equipe de sustentabilidade do Mercado Livre. 


\title{
artigos GIFE
}

Supervisão: José Marcelo Zacchi e Gustavo Bernardino

Coordenação: Carolina Magosso

Produção editorial: Gleice Regina Guerra

Apoio: Graziela Santiago

Comitê de seleção: Ana Lúcia D'Império Lima, Fábio Silva

Tsunoda, Laura Leal e Lívia Menezes Pagotto

Diagramação: Alastra, Comunica.

Impressão: Forma Certa

ISSN: 2674-8061

DOI: doi.org/10.33816/gife.20200202a1

(C) 2020 GIFE - Grupo de Institutos Fundações e Empresas

\section{(c) (i) ()}

Este material é disponibilizado sob a licença Creative Commons Atribuição Não Comercial 4.0 Internacional. http://creativecommons.org/licenses/by-nc/4.0

As opiniões e análises expressas nesta publicação não necessariamente refletem as do GIFE.

\author{
Apoio institucional \\ Alana \\ Ford Foundation \\ Fundação Bradesco \\ Fundação Lemann \\ Fundação Tide Setubal \\ Instituto Unibanco \\ Laudes Foundation
}

